\title{
Estimation of clonal diversity in HTLV-1 infection
}

\author{
Daniel J Laydon ${ }^{*}$, Anat Melamed ${ }^{1}$, Aaron Sim², Nicolas A Gillet ${ }^{1,3}$, Kathleen Sim ${ }^{4}$, Sam Darko ${ }^{5}$, J Simon Kroll ${ }^{4}$, \\ Daniel C Douek ${ }^{5}$, David A Price ${ }^{5,6}$, Charles RM Bangham', Becca Asquith ${ }^{1}$
}

From 16th International Conference on Human Retroviruses: HTLV and Related Viruses

Montreal, Canada. 26-30 June 2013

Within hosts, Human T-Lymphotropic Virus Type-1 (HTLV-1) is spread through de novo infection and infected cell proliferation, producing multiple $\mathrm{T}$ cell clones (infected cells with the same genomic proviral integration site). Between hosts, the number of clones observed from a $10 \mu \mathrm{g}$ sample of DNA varies by up to three orders of magnitude. The question arises: what is the total number of clones in the host from which that sample was drawn? Considering each clone as a "species", the question becomes analogous to the "unseen species problem" in population ecology. We tested four species richness (number of species) estimators, and a novel approach, "DivE", using three independent datasets: (i) viral populations from patients infected with HTLV-1, (ii) T cell antigen receptor clonotype repertoires, and (iii) microbial data from infant faecal samples. In all datasets, DivE was substantially more accurate than the ecological estimators, which were strongly biased by sample size when applied to datasets where the majority of species was not already present. $D i v E$ can also be used to estimate with accuracy the population clone structure from small samples. Previous estimates of HTLV-1 clone diversity in vivo were in the order of 102, and have increased in line with method sensitivity. In contrast, the mean estimated number of clones in the circulation of a single host (asymptomatic carriers and patients with chronic inflammation) by DivE was more than two logs higher than previously estimated. These estimates will inform our understanding of the dynamics and pathogenesis of HTLV-1 infection.

\section{Authors' details}

'Section of Immunology, Wright-Fleming Institute, Imperial College School of Medicine, London, UK. ${ }^{2}$ Centre for Integrative Systems Biology and Bioinformatics, South Kensington Campus, Imperial College, London, UK. ${ }^{3}$ Department of Molecular and Cellular Epigenetics, University of Liège, Liège, Belgium. ${ }^{4}$ Section of Paediatrics, Wright-Fleming Institute, Imperial College School of Medicine, London, UK. ${ }^{5}$ Vaccine Research Center, National Institutes of Health, Bethesda, USA. ${ }^{6}$ Institute of Infection and Immunity, Cardiff University School of Medicine, Cardiff, Wales, UK.

Published: 7 January 2014

doi:10.1186/1742-4690-11-S1-050

Cite this article as: Laydon et al:: Estimation of clonal diversity in HTLV-1 infection. Retrovirology 2014 11(Suppl 1):O50.

Submit your next manuscript to BioMed Central and take full advantage of:

- Convenient online submission

- Thorough peer review

- No space constraints or color figure charges

- Immediate publication on acceptance

- Inclusion in PubMed, CAS, Scopus and Google Scholar

- Research which is freely available for redistribution
() Biomed Central

\footnotetext{
${ }^{1}$ Section of Immunology, Wright-Fleming Institute, Imperial College School of Medicine, London, UK

Full list of author information is available at the end of the article
} 